\title{
Marktordnung durch Haftung
}

Legitimation, Reichweite und Steuerung der Haftung auf Schadensersatz zur Durchsetzung marktordnenden Rechts

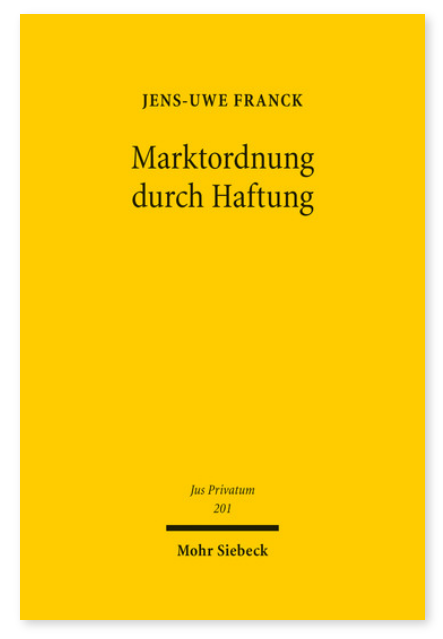

2016. XXXVIII, 710 Seiten. JusPriv 201

ISBN 978-3-16-154093-6

DOI 10.1628/978-3-16-154093-6

eBook PDF 154,00€

ISBN 978-3-16-153802-5

Leinen $154,00 €$
Schadenshaftung zur Durchsetzung marktordnenden Rechts gewinnt in Deutschland und Europa an Bedeutung. Diese Entwicklung relativiert die im Bürgerlichen Recht angelegten Grenzen deliktsrechtlicher Haftung. Ökonomische Einsichten helfen, die damit einhergehenden Risiken einer Fehlsteuerung zu identifizieren und Korrekturpotentiale im Haftungsrecht zu erkennen. Vor allem mit Blick auf das Kapitalmarkt- und Kartellrecht untersucht Jens-Uwe Franck, wie

Haftungsvoraussetzungen und Haftungsfolgen dazu beitragen können, überschießende oder zu kurz greifende Präventionswirkungen zu vermeiden. Diese an zahlreichen Beispielen entfaltete Analyse ruht auf einer Klärung von Grundsatzfragen der Legitimation und Funktion von Haftung als Durchsetzungsinstrument und ihres unionsrechtlichen Rahmens.

Jens-Uwe Franck ist Inhaber des Lehrstuhls für Bürgerliches Recht, Handels- und Kartellrecht an der Universität Mannheim.

Jetzt bestellen:

https://mohrsiebeck.com/buch/marktordnung-durch-haftung-9783161540936?no_cache=1

order@mohrsiebeck.com

Telefon: +49 (0)7071-923-17

Telefax: +49(0)7071-51104 